Check for updates

Cite this: RSC Adv., 2019, 9, 32403

\title{
Efficient methane-to-acetylene conversion using low-current arcs
}

\author{
Duy Khoe Dinh, (DD *ab Dae Hoon Lee, ${ }^{\text {*ab }}$ Young-Hoon Song, ${ }^{\text {ab }}$ Sungkwon Jo, ${ }^{\text {ab }}$ \\ Kwan-Tae Kim, ${ }^{\mathrm{b}}$ Muzammil lqbal $\mathbb{D D}^{\mathrm{b}}$ and Hongjae Kang ${ }^{\mathrm{b}}$
}

The proliferation of natural gas production had led to increased utilization of methane as a raw material for chemicals. The most significant bottleneck in this process is the high activation energy of methane. This paper reports the direct conversion of methane to acetylene in a novel rotating arc driven by $A C$ electrical power. By feeding a sufficiently high concentration of $\mathrm{CH}_{4}$ (greater than $43 \%$ ) diluted in $\mathrm{H}_{2}$ (the discharge gas) through the arc column, a low specific energy requirement (SER) of $10.2 \mathrm{~kW} \mathrm{~h} \mathrm{~kg}^{-1} \mathrm{C}_{2} \mathrm{H}_{2}$ was achieved. The use of hydrogen as the discharge gas strongly suppressed soot formation during the methane conversion process under high methane concentration conditions, resulting in a carbon balance of greater than $95 \%$ and a $\mathrm{C}_{2} \mathrm{H}_{2}$ selectivity of greater than $90 \%$ while maintaining a methane conversion rate of greater than $70 \%$, depending on the conditions. The novel rotating arc enabled the elongation of the arc column itself, which controlled heat loss and improved the energy use for reaction. The ability to control the arc length based on low-current type arc generation has additional benefits for reaction enhancement. These results demonstrate that arc control, optimization of the reaction conditions, and a full understanding of reaction pathway are viable means for the energy-efficient direct conversion of methane to acetylene.

Received 1st August 2019

Accepted 3rd October 2019

DOI: $10.1039 / c 9 r a 05964 d$

rsc.li/rsc-advances synthetic oil through polymerization. However, because the reforming process for producing syngas from methane begins with the decomposition of methane, a very stable compound, a large amount of energy is required for the methane activation process, making it difficult to achieve economic efficiency in the overall process. Thus, various process concepts for the production of $\mathrm{C}_{2}$ or higher compounds through the direct conversion of methane without a synthesis gas step have been proposed. Representative examples of such processes include the oxidative coupling of methane (OCM) and non-oxidative conversion of methane (nonOCM) processes. ${ }^{2-4}$

The OCM process, which allows the synthesis of $\mathrm{C}_{2}$ chemicals via the coupling of methane, has been developed for decades. However, this method has two important drawbacks: (1) the yield of $\mathrm{C}_{2}$ chemicals is low (typically less than $20 \%$, even considering the overall sum of $\mathrm{C}_{2}$ species), and (2) the production of $\mathrm{CO}_{2}$ is inevitable due to the oxidizer in the reactant stream. Recently, a methane conversion of approximately $50 \%$ with $50 \%$ ethylene selectivity has been reported using a single-site iron catalyst at $1363 \mathrm{~K}$, and a high ethylene yield of $25.7 \%$ has been achieved in plasma-catalyst hybrid reactor.,6 However, the high-temperature condition, poor reliability of the catalyst, and the inability to obtain a selectivity greater than $50 \%$ remain obstacles to the commercial feasibility of this technology.

In addition to the OCM and nonOCM processes, which are based on catalytic processes, plasma treatment has been
${ }^{a}$ University of Science and Technology (UST), 217 Gajeong-ro Yuseong-gu, Daejeon 34113, Republic of Korea

${ }^{b}$ Korea Institute of Machinery and Materials, 156 Gajeongbuk-ro, Yuseong-gu, Daejeon 34103, Republic of Korea.E-mail:khoedd@kimm.re.kr; dhlee@kimm.re.kr 
proposed as an alternative tool for methane conversion. Plasma can achieve higher temperatures $(>2000 \mathrm{~K})$ that a typical burner or heater, and can also produce chemically active species such as radicals, ions, and high-energy electrons, which can promote the initial activation of methane via the formation of a methyl radical. ${ }^{7,8}$

In the direct conversion of methane, the composition of the main products varies depending on the reaction conditions or the degree to which methane is thermally activated. A lowtemperature process such as OCM will result in $\mathrm{C}_{2} \mathrm{H}_{6},{ }^{2-4}$ while mid-scale thermal activation such as that achieved using nonOCM processes, which have a temperature range of 1000-1500 $\mathrm{K}$, will produce $\mathrm{C}_{2} \mathrm{H}_{4}$ as the main product. ${ }^{5,6}$ However, in the high-temperature plasma process $(>1500 \mathrm{~K}), \mathrm{C}_{2} \mathrm{H}_{2}$ is the main product. ${ }^{9-11}$ At such high temperature conditions, high methane conversion and high $\mathrm{C}_{2} \mathrm{H}_{2}$ yield are obtainable. ${ }^{2-4,9-11}$

Once high conversion and selectivity for a specific $\mathrm{C}_{2}$ are obtained, a range of $\mathrm{C}_{2}$ chemicals can be produced via interconversion between $\mathrm{C}_{2}$ species. ${ }^{12-14}$ Considering this background, in this work, an efficient plasma process to achieve the high conversion of methane and high selectivity for $\mathrm{C}_{2} \mathrm{H}_{2}$ is proposed.

\subsection{Plasma process for direct conversion of methane}

Plasma can be generated under different conditions; the gas temperature can range from close to room temperature to thousands of degrees Kelvin. ${ }^{15-22}$ In non-thermal plasma, the electron temperature is several $\mathrm{eV}$, while the temperature of the gas molecules is low, being close to room temperature. In comparison, thermal plasma has a lower electron temperature, but a higher heavy molecule temperature. Thus, thermal plasma generation, in which the electron temperature is relatively low, but the density of charged species and gas temperature are relatively high, should be employed to create high temperature conditions for methane activation.

In general, plasma is generated using a high electric field, and the discharge process inevitably consumes electric power, which is an expensive energy source. The generation of plasma itself presents an energy conversion issue; only part of the input electrical energy is delivered to or adsorbed by the plasma. Moreover, the energy distribution of the activated species is based on non-equilibrium phenomena. Not all of the energy in generated plasma can be delivered for reactant activation. Thus, the generation of plasma results in inefficient energy usage in general; this inefficiency is one reason that plasma is not widely applied in chemical processes. However, the characteristics of plasma can be positively applied in methane activation to produce $\mathrm{C}_{2}$ chemicals. The required conditions for a high yield of $\mathrm{C}_{2} \mathrm{H}_{2}$ from methane are: (1) a high gas temperature (much higher than $1500 \mathrm{~K}$ ), (2) a short reaction time (quenching within a few milliseconds), and (3) the presence of an additive to suppress solid carbon generation. Conditions (1) and (2) can be provided by thermal plasma.

High-temperature. In the equilibrium condition, a temperature of approximately $3000 \mathrm{~K}$ is required to provide the highest yield in methane activation. ${ }^{23}$ Given this, the application of partial oxidation, regenerative pyrolysis, or indirect heating via combustion gas are not appropriate, as these techniques cannot meet this requirement. Although studies based on partial oxidation for the direct conversion of methane have been reported, ${ }^{24-29}$ the generation of synthesis gas and other hydrocarbons due to the relatively low temperature reduces the $\mathrm{C}_{2} \mathrm{H}_{2}$ yield. ${ }^{28}$ Additionally, little progress has been made towards overcoming the temperature and material issues in regenerative methane pyrolysis using combustion heat and regenerative heat transfer. ${ }^{24,30-33}$

In comparison, in the case of thermal plasma, the methane is heated not by the chemical energy released during combustion (or oxidation), but instead via direct joule heating of the reactant inside the arc via the discharge process and direct heat transfer from the arc to the surrounding reactant or methane. ${ }^{34}$ The principle can enable the reactant to reach temperatures above $2000 \mathrm{~K}$, depending on the power supplied. The main concern in plasma heating is its efficiency. The efficiency of the conversion from electric energy to thermal energy or heat must be optimized in order for plasma treatment to be economically feasible. Currently, the only commercialized plasma process for methane activation is the Hüels process, which is reported to have a cost of approximately $12.1 \mathrm{~kW} \mathrm{~h} \mathrm{~kg}^{-1} \mathrm{C}_{2} \mathrm{H}_{2} \cdot{ }^{23,35}$ The equation for the reaction is shown in eqn (1). The absolute enthalpy difference between the reactant and the product is approximately $4 \mathrm{~kW} \mathrm{~h} \mathrm{~kg}{ }^{-1} \mathrm{C}_{2} \mathrm{H}_{2}$; however, taking into account the energy required for the activation of methane, the cost of the Hüels process is reasonable.

$$
2 \mathrm{CH}_{4} \rightarrow \mathrm{C}_{2} \mathrm{H}_{2}+3 \mathrm{H}_{2}, \Delta H^{0}=377 \mathrm{~kJ} \mathrm{~mol}^{-1}
$$

In addition, an arc process using a DC power source has been attempted to rotate the arc using a magnetic force to reduce electrode erosion and increase the possibility of the methane contacting the arcs. ${ }^{36-38}$

Fast quenching. At sufficiently high temperatures, fast quenching of the reaction to prevent the successive thermal pyrolysis of $\mathrm{C}_{2} \mathrm{H}_{2}$ is required to obtain a high yield of $\mathrm{C}_{2} \mathrm{H}_{2}$. Successive thermal pyrolysis results in the generation of solid carbon, which reduces the $\mathrm{C}_{2} \mathrm{H}_{2}$ yield and increases the reaction temperature required for the production of $\mathrm{C}_{2} \mathrm{H}_{2}$. Given this, it is essential to immediately lower the reaction temperature after the formation of acetylene to fix the product in the acetylene state. At a reaction temperature of $1800 \mathrm{~K}$ or higher, the reaction time should be limited to approximately $4 \mathrm{~ms}$ in order to guarantee $\mathrm{a}_{2} \mathrm{H}_{2}$ yield greater than $70 \%$, as shown in Fig. $1 .^{38}$

Additives. The pyrolysis of methane begins with the breakage of the $\mathrm{C}-\mathrm{H}$ bond followed by chain reactions initiated by methyl radicals. The details of this process have been described thoroughly in the literature. ${ }^{39-43}$ During the course of the reaction, the most important concern is avoiding the generation of solid carbon. The generation of solid carbon will decrease the acetylene yield and the operation of the reactor will be prohibited. One means of suppressing carbon generation is the addition of hydrogen. Because hydrogen is produced in the course of methane conversion to acetylene, it can be recirculated into the reactor. Kinetically, the effects of hydrogen addition are: (1) suppression of soot formation, which results in higher 


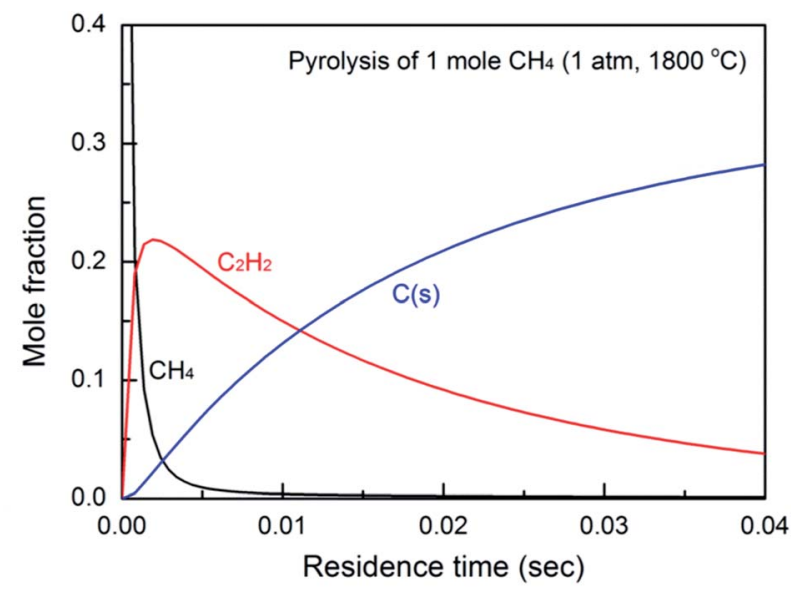

Fig. 1 Effect of residence time (reaction time) on the product yield, calculated based on a simplified reaction model proposed by Holmen. ${ }^{38}$

selectivities towards hydrocarbon species and (2) inhibition of methane conversion. Details of the kinetic aspects can be found in ref. 39, 42 and 43.

In light of the above, arc plasma is an efficient tool for the activation of methane to form acetylene, and has been investigated for decades. However, there is still room for improvement in this process, including reduction of the process cost. This work introduces a systematic approach for the cost optimization of the process by enhancing the reactor design, optimizing the reaction conditions, and employing a lowcurrent AC power.

\section{Materials and methods}

\subsection{Novel rotating arc reactor and experimental setup}

The conventional rotating arc reactor has been reported to be an efficient tool to convert fuels into value-added chemicals. ${ }^{44-48}$ The principle of the conventional rotating arc is similar to that of the gliding arc. Following ignition at the shortest gap between the electrodes, the arc column is convected downward via elongation of the arc itself. The end of one side of the arc reaches the tip of the high-voltage electrode, the arc detaches, and the process is then repeated. However, this design can be modified by connecting a converging nozzle in the reactor at a designed distance downstream from the high-voltage electrode, called novel rotating arc reactor. In this new setup, the arc column is stably anchored to the tip of the high-voltage electrode without detachment. The anchoring of the arc at the nozzle throat results in a highly thermal volume inside the nozzle structure. The formation of a stable elongated arc reduces the energy losses due to repeated ignition with variable arc lengths. ${ }^{49}$ The high temperature environment in the modified arc reactor has been effectively applied in endothermic reactions such as $\mathrm{NH}_{3}$ decomposition and the dry reforming process. ${ }^{4-51}$ In this work, the same principle is used to induce the strongly endothermic process of methane activation to form acetylene.
The main materials used in the experiment are shown in Fig. 2a. The novel reactor was constructed using a conical copper high-voltage electrode (15 $\mathrm{mm}$ diameter) enveloped by a cylindrical stainless-steel ground (17 $\mathrm{mm}$ in diameter). The reactor was connected to a nozzle with a diameter of $6 \mathrm{~mm}$ joined to a straight tube of the same diameter $(6 \mathrm{~mm})$ to ensure that the stable elongated arcs operated in a rather wide range of electrical energy. The distance between the high-voltage electrode tip and the nozzle was approximately $20 \mathrm{~mm}$.

The methane feedstock was diluted in the discharge gases at Gate 1 to pass through the arc column $\left(\mathrm{CH}_{4}\right.$ premixed with the discharge gas, Case 1$)$ or separately fed at Gate $2\left(\mathrm{CH}_{4}\right.$ nonpremixed with the discharge gas, Case 2). In this study, the discharge gases were pure $\mathrm{H}_{2}$ or a mixture of $\mathrm{H}_{2}$ and $\mathrm{Ar}$, and were tangentially injected at Gate 1 to form elongated stable arcs. The arcs were rotated inside the reactor using rotating flows as described in previous reports. ${ }^{49}$ As mentioned previously, in order to prevent the decomposition of $\mathrm{C}_{2} \mathrm{H}_{2}$ to solid carbon, a fast quenching process is required. Further cooling does not have an impact once the temperature is below the value required for further thermal pyrolysis of the product. Considering this, the heat transfer via the walls was sufficient to quench the reaction. The reduced diameter of the reactor provided a large surface-to-volume ratio for increased wall heat transfer. A thermocouple was placed $60 \mathrm{~mm}$ downstream from the nozzle to measure the outlet gas temperature. Although the measured temperature did not exactly reflect the temperature inside the reaction chamber because of the non-uniform temperature distribution inside the reactor, the thermocouple reading could be used to compare the thermal environment inside the reactor under different experimental conditions.

An AC plasma power supply providing a voltage up to $12 \mathrm{kV}$ and current of several amperes (i.e. RMS current lower than 10 A) at a frequency of $20 \mathrm{kHz}$ was employed to generate the stable elongated arcs. Depending on the gas discharge and electrical power condition, the value of current can vary from $1 \mathrm{~A}$ to $10 \mathrm{~A}$. The AC power provides high voltage transformation driven by sinusoidal wave input. A Tektronix P6015A high voltage probe and Tektronix TCP303 current probe were employed to measure the voltage and current, which were used to calculate the applied electric power using an oscilloscope (Tektronix TDS5054B). The plasma voltage and current waveforms were shown in Fig. 2b for several arcing events, which indicated good in-phase voltage and current characteristics. An oscillogram of the well stable elongated arcs was shown in Fig. 2c. The plasma power was calculated by the direct integration of the product of the voltage and current as expressed in eqn (2).

$$
\text { Plasma power }=\frac{1}{T} \int_{0}^{T} V \times I \mathrm{~d} t(W)
$$

here, $V$ denotes the voltage $(\mathrm{V})$ and $I$ denotes the current (A). In our calculation, the voltage and current are in phase.

The sampling rate of the voltage and current was 2 million samples per second or $2 \mathrm{MHz}$, which was sufficiently high to perform the direct integration considering the AC frequency of 20 $\mathrm{kHz}$. In the proposed reactor configuration, the arc spot in the ground electrode was rotated; because of this, no thermal erosion 
of the reactor wall was observed. However, the arc spot was focused on the tip of the high-voltage electrode. To prevent its thermal erosion, active cooling was applied to the high-voltage electrode.

\subsection{Analysis method}

To calculate the mass balance of the product, $\mathrm{N}_{2}$ was added to the reactor in the downstream region, where the gas temperature was low enough to completely inhibit further reactions between $\mathrm{N}_{2}$ and the product. The product mainly included gaseous species such as $\mathrm{CH}_{4}, \mathrm{C}_{2} \mathrm{H}_{2}, \mathrm{H}_{2}$, Ar, and other hydrocarbons. Therefore, after being passed through a cold trap, the sampled product was analyzed using a gas chromatograph (GC) that could measure $\mathrm{H}_{2}, \mathrm{CO}, \mathrm{CO}_{2}$, and $\mathrm{N}_{2}$ with a thermal conductivity detector (TCD, Carboxen1010) and hydrocarbons with carbon numbers of up to 4 with a flame ionization detector (FID, HP-AL/KCL).

The methane conversion was calculated using eqn (3) as follows:

$$
X_{\mathrm{CH}_{4}}=\left(\frac{\left[\mathrm{C}_{\mathrm{CH}_{4}}\right]_{\mathrm{in}}-\alpha\left[\mathrm{C}_{\mathrm{CH}_{4}}\right]_{\text {out }}}{\left[\mathrm{C}_{\mathrm{CH}_{4}}\right]_{\text {in }}}\right) \times 100(\%)
$$

where $\alpha$ is the correction factor to account for the gas expansion, which was calculated using eqn (4) as follows:
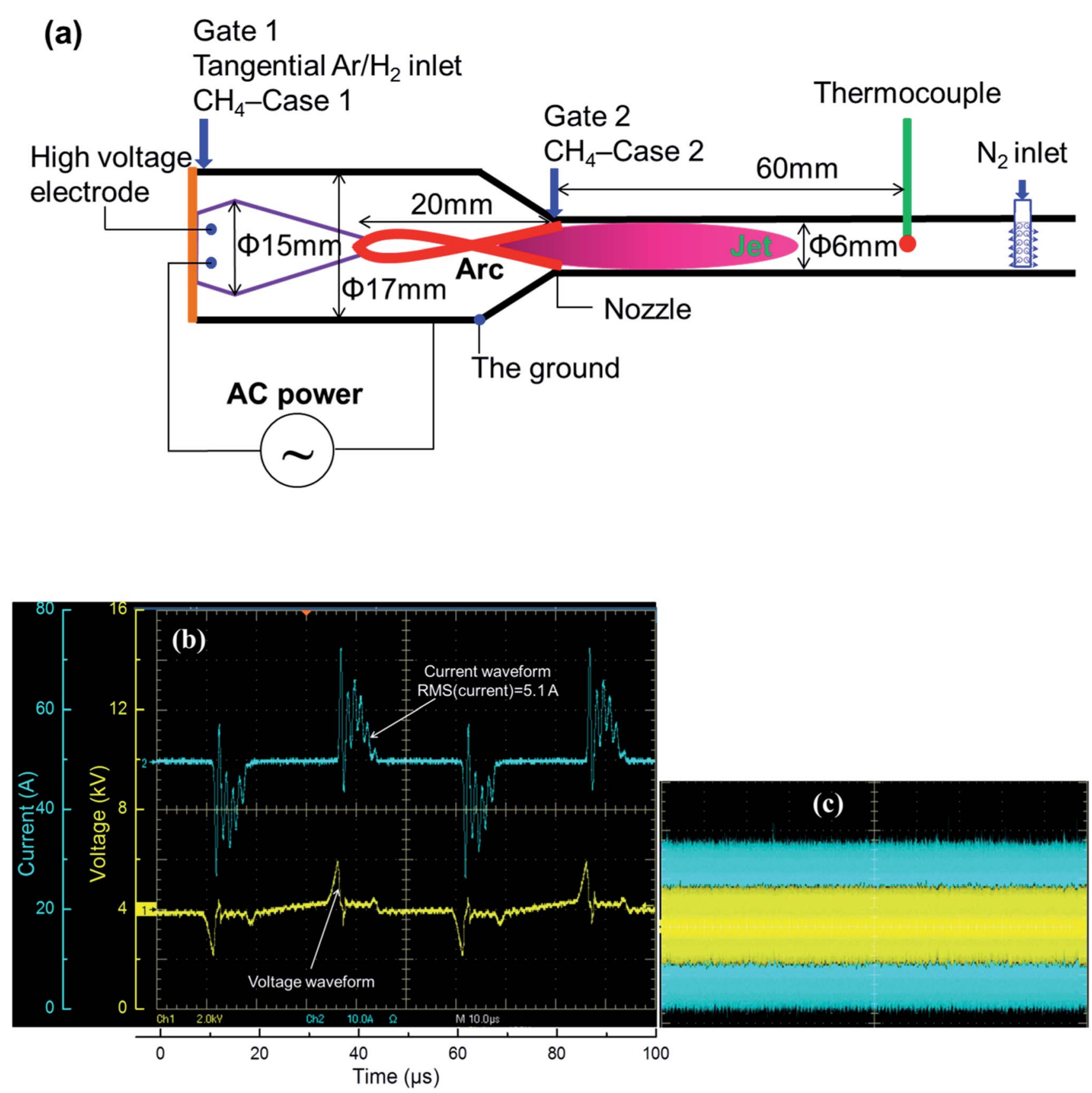

Fig. 2 (a) Novel rotating arc reactor with a stable elongated arc, (b) oscillogram representing the plasma voltage and current waveforms (yellow line: voltage; blue line: current), overall time span: $100 \mu \mathrm{s}$, at the condition of $850 \mathrm{~W}$ power, $\mathrm{H}_{2}=8 \mathrm{SLMP}$ and $\mathrm{CH}_{4}=2 \mathrm{SLPM}$, (c) oscillogram representing the voltage and current characteristics of the stably elongated arc having overall time span of 0.1 second. 


$$
\alpha=\frac{\left[\mathrm{C}_{\mathrm{N}_{2}}\right]_{\text {in }}}{\left[\mathrm{C}_{\mathrm{N}_{2}}\right]_{\text {out }}}
$$

where $\left[\mathrm{C}_{\mathrm{CH}_{4}}\right]_{\text {in }}$ and $\left[\mathrm{C}_{\mathrm{N}_{2}}\right]_{\text {in }}$ are the concentrations of $\mathrm{CH}_{4}$ and $\mathrm{N}_{2}$ measured after passing through the reactor in the absence of plasma, while $\left[\mathrm{C}_{\mathrm{CH}_{4}}\right]_{\text {out }}$ and $\left[\mathrm{C}_{\mathrm{N}_{2}}\right]_{\text {out }}$ represent their concentrations in the effluent gas in the presence of plasma, respectively.

The selectivity for hydrocarbons with a carbon number of 2 $\left(\mathrm{C}_{2} \mathrm{H}_{y}\right)$ and the carbon balance $\left(\mathrm{C}_{\mathrm{b}}\right)$ are expressed in eqn (5) and (6), respectively.

$$
\begin{gathered}
\operatorname{SEL}\left(\mathrm{C}_{2} \mathrm{H}_{y}\right)=\frac{2 \alpha\left[\mathrm{C}_{\mathrm{C}_{2} \mathrm{H}_{y}}\right]_{\text {out }}}{\left[\mathrm{C}_{\left.\mathrm{CH}_{4}\right]_{\text {in }}} \times X_{\mathrm{CH}_{4}}\right.} \times 100(\%) \\
C_{\mathrm{b}}=\left(\frac{\alpha\left(\left[\mathrm{C}_{\left.\mathrm{CH}_{4}\right]_{\text {out }}}+\sum_{x=2,3,4} x\left[\mathrm{C}_{\mathrm{C}_{x} \mathrm{H}_{y}}\right]_{\text {out }}\right)\right.}{\left[\mathrm{C}_{\mathrm{CH}_{4}}\right]_{\text {in }}}\right) \times 100(\%)
\end{gathered}
$$

where $\left[\mathrm{C}_{\mathrm{C}_{x} \mathrm{H}_{y}}\right]_{\text {out }}$ represents the concentration of hydrocarbons $\left(\mathrm{C}_{x} \mathrm{H}_{y}\right)$ in the effluent gas, $x=2,3,4$.

The energy cost of acetylene production as represented by the Specific Energy Requirement (SER) was calculated using eqn (7).

$$
\mathrm{SER}=\frac{\left(\frac{P_{\text {in }}}{1000 \times 3600}\right)}{m_{\mathrm{C}_{2} \mathrm{H}_{2}}}\left(\mathrm{~kW} \mathrm{~h} \mathrm{~kg}{ }^{-1} \mathrm{C}_{2} \mathrm{H}_{2}\right)
$$

where $m_{\mathrm{C}_{2} \mathrm{H}_{2}}$ is the mass flow rate of $\mathrm{C}_{2} \mathrm{H}_{2}\left(\mathrm{~kg} \mathrm{~s}^{-1}\right)$.

The acetylene concentration in the product $\left(\left[\mathrm{C}_{2} \mathrm{H}_{2}\right]_{\text {product }}\right)$ was defined using eqn (8):

$$
\left[\mathrm{C}_{2} \mathrm{H}_{2}\right]_{\text {Product }}=\frac{\left[\mathrm{C}_{\mathrm{C}_{2} \mathrm{H}_{2}}\right]_{\text {out }}}{\left[\mathrm{C}_{\mathrm{CH}_{4}}\right]_{\text {out }}+\left[\mathrm{C}_{\mathrm{H}_{2}}\right]_{\text {out }}+\left[\mathrm{C}_{\mathrm{Ar}}\right]_{\text {out }}+\sum_{x=2,3,4} x\left[\mathrm{C}_{\left.\mathrm{C}_{x} \mathrm{H}_{y}\right]_{\text {out }}}\right.}
$$

where $\left[\mathrm{C}_{\mathrm{C}_{2} \mathrm{H}_{2}}\right]_{\text {out }},\left[\mathrm{C}_{\mathrm{Ar}}\right]_{\text {out }}$, and $\left[\mathrm{C}_{\mathrm{H}_{2}}\right]_{\text {out }}$ represent the concentrations of acetylene, argon, and hydrogen in the effluent gas, respectively.

The specific energy input (SEI) was obtained from eqn (9):

$$
\mathrm{SEI}=\frac{P_{\mathrm{in}} \times 60 / 1000}{F_{\mathrm{CH}_{4}}^{\mathrm{i}}+F_{\mathrm{H}_{2}}^{\mathrm{i}}+F_{\mathrm{Ar}}^{\mathrm{i}}}\left(\mathrm{kJ} \mathrm{L} \mathrm{L}^{-1}\right)
$$

where $F_{\mathrm{CH}_{4}}^{\mathrm{i}}, F_{\mathrm{H}_{2}}^{\mathrm{i}}$, and $F_{\mathrm{Ar}}^{\mathrm{i}}$ are the flowrates of $\mathrm{CH}_{4}, \mathrm{H}_{2}$, and $\mathrm{Ar}$ (SLPM), respectively, and $P_{\text {in }}$ is the real plasma power calculated by integrating the product of voltage and current as in eqn (2).

\section{Results}

\subsection{Effect of the methane inlet position}

The novel rotating arc was designed such that the discharge gas was introduced tangentially to generate a swirling flow inside the reactor, which rotated and stabilized the arc. Meanwhile, methane was fed in at one of two different positions: either premixed with the discharge gas at Gate 1 (Case 1) or separately at Gate 2 (Case 2) as shown in Fig. 2. Comparison of these methane inlet positions is important in optimizing the reactor design and to have a full understanding of the characteristics of methane activation in the arc region and the jet region.

Introducing the methane via Gate 1 could affect the generation of the arc. The physical properties of the gas are a critical factor during arc generation. An electronegative gas could potentially degenerate high energy electrons, and nonmonatomic gas molecules could be decomposed during arc generation. In terms of hydrocarbon species, the generation of solid carbon would also have a negative effect on arc generation. However, introducing $\mathrm{CH}_{4}$ at Gate 1 rather than Gate 2 would increase the probability that the gas molecules would come into contact with the arc and promote heat transfer from the arc column to the gas molecules. Thus, experimental observation was required to assess which strategy could better achieve the conversion of methane to acetylene.

The experiments were conducted at different electrical energies with a fixed reactant composition (4 SLPM of Ar, 4 SLPM of $\mathrm{H}_{2}$, and 3 SLPM of $\mathrm{CH}_{4}$ ). The experimental results showed that when the methane was diluted in the discharge gas before passing through the arc column (Case 1), the methane conversion was much higher and the acetylene selectivity was slightly higher than when the reactant was fed in downstream of the arc column (Case 2). For example, at an SEI of $4.6 \mathrm{~kJ} \mathrm{~L}^{-1}$, the conversion in Case 1 was approximately 2.5 times higher than that in Case 2 (73.7\% vs. $29.5 \%$, respectively). This showed that a significant portion of the methane was converted in the arc region (approximately $44.2 \%$ conversion in the arc region at an SEI of $4.6 \mathrm{~kJ} \mathrm{~L}^{-1}$ ), as shown in Fig. 3a. The efficient conversion in the arc region can be explained by the impact of the electron direct activation, and the higher temperature environment resulting from the gas phase heat transfer from the arc. Fig. 3b shows the higher selectivity towards $\mathrm{C}_{2} \mathrm{H}_{4}$ and $\mathrm{C}_{2} \mathrm{H}_{6}$ in the jet region than in the arc region, which indirectly indicates that the temperature in the jet area is much lower than that in the arc area. Therefore, premixing the methane with the discharge gas to pass through the arc column resulted in a dramatically lower energy requirement for acetylene production in the novel arc reactor, as shown in Fig. 3c.

Increasing the electric power increased the temperature inside the reactor, resulting in increased methane conversion in both cases. However, the effect of increasing the electric power on the SER differed for the two cases. The SER in Case 2 was dramatically reduced when the electrical power was increased, whereas that in Case 1 remained unchanged. For example, increasing the SEI from $3.4 \mathrm{~kJ} \mathrm{~L}^{-1}$ to $4.6 \mathrm{~kJ} \mathrm{~L}^{-1}$ reduced the SER from $64.8 \mathrm{~kW} \mathrm{~h} \mathrm{~kg}^{-1} \mathrm{C}_{2} \mathrm{H}_{2}$ to $32.3 \mathrm{~kW} \mathrm{~h} \mathrm{~kg}^{-1} \mathrm{C}_{2} \mathrm{H}_{2}$ in Case 2, while the SER in Case 1 remained constant at $12 \mathrm{~kW} \mathrm{~h} \mathrm{~kg}^{-1}$ $\mathrm{C}_{2} \mathrm{H}_{2}$, as shown in Fig. 3c. This indicates that the further addition of electrical power increased the temperature and volume of the jet region, reducing the temperature difference between the arc and jet region. Therefore, the difference in energy cost (SER) between the two cases was reduced. This comparison shows that the methane should be premixed with the discharge gas in order to achieve a lower energy cost in arc technology. 

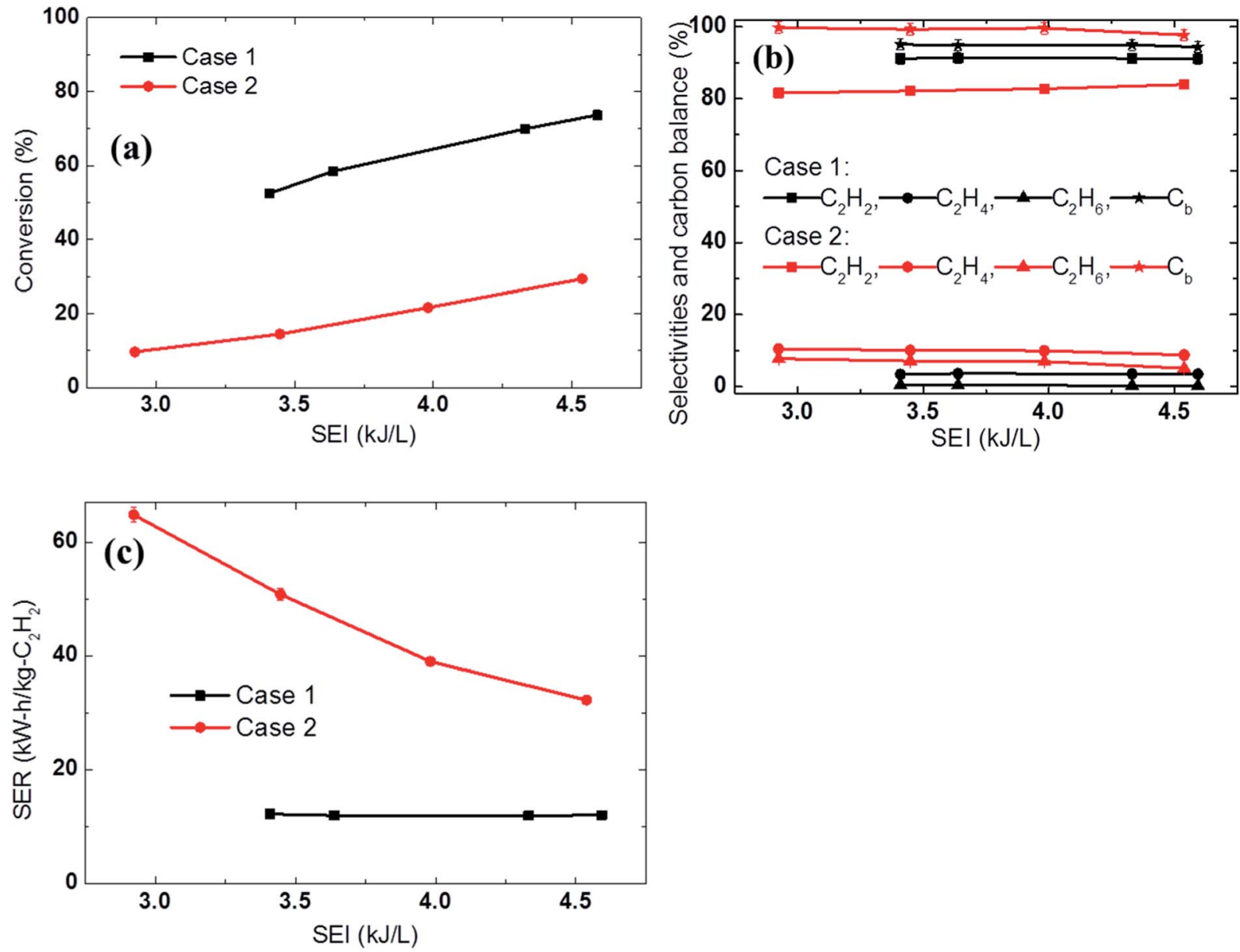

Fig. 3 Effect of the methane feeding method on the (a) conversion, (b) selectivities and carbon balance, and (c) SER using 4 SLPM of Ar, 4 SLPM of $\mathrm{H}_{2}$, and $3 \mathrm{SLPM}$ of $\mathrm{CH}_{4}$.

\subsection{Effect of the methane concentration (methane feed rate)}

Previous studies have shown that the methane feed rate or the methane concentration is the main parameter affecting the energy cost of acetylene production. ${ }^{23,35}$ In this study, we reexamined the effect of the methane feed rate on the SER by using different discharge gases: either $\mathrm{H}_{2}$ (8 SLPM) or a mixture of $\mathrm{H}_{2}$ and $\mathrm{Ar}$ (4 SLPM $\mathrm{H}_{2}$ and 4 SLPM Ar). The methane feedstock was adjusted from 1 to 8 SLPM in the $\mathrm{H}_{2}$ discharge gas and from 1 to 6 SLPM in the $\mathrm{H}_{2}$ and Ar mixture; the supplied electrical power was set as $2 \mathrm{~kW}$. As previously mentioned, the methane feedstock was diluted in the discharge gases before being passed through the arc column. The differences in the composition of the reactants led to slight variations in the measured plasma power (the real plasma power) as shown in Fig. 4 a. The plasma power increased slightly with the higher methane feed rate.

Fig. $4 \mathrm{~b}$ shows that the SER quickly decreased with increasing methane concentration. For example, when a sufficiently high amount of methane was introduced, the SER value could be reduced to $9.8 \mathrm{~kW} \mathrm{~h} \mathrm{~kg}^{-1} \mathrm{C}_{2} \mathrm{H}_{2}$ in the $\mathrm{H}_{2}$ discharge gas and 11.2 $\mathrm{kW} \mathrm{h} \mathrm{kg}{ }^{-1} \mathrm{C}_{2} \mathrm{H}_{2}$ in the $\mathrm{H}_{2}$ and $\mathrm{Ar}$ mixture, respectively. In contrast, at low methane feed rate, a considerable amount of the electrical energy was wasted in heating the discharge gases, reducing the fraction of electrical energy used to induce the conversion of methane to acetylene, resulting in a high energy cost. Therefore, increasing the methane feed rate was beneficial in terms of reducing the SER; however, it also led to higher soot formation and lower acetylene selectivity. For example, the carbon balance was reduced from $99.8 \%$ to $95 \%$ in the $\mathrm{H}_{2}$ discharge gas and from $99.6 \%$ to $85.5 \%$ in the $\mathrm{Ar}$ and $\mathrm{H}_{2}$ mixture with increased methane concentration, as shown in Fig. 5b. The methane conversion also decreased as the methane concentration in the feed was increased, as shown in Fig. 5a.

\subsection{Effect of the discharge gas}

The $\mathrm{H}_{2}$ dilution $\left(\mathrm{H}_{2} / \mathrm{CH}_{4}\right.$ ratio) has a strong effect on the kinetics of the methane conversion. Increasing the $\mathrm{H}_{2} / \mathrm{CH}_{4}$ ratio accelerates the backward reaction, inhibiting methane conversion. Specifically, greater $\mathrm{H}_{2}$ dilution results in a reduction in the $\mathrm{CH}_{3}$ radical concentration via the reaction shown in eqn (10) below. ${ }^{33,38,39}$ Additionally, hydrogen dilution also strongly depresses carbon formation, increasing the selectivity for acetylene. .33,38,39 $^{2}$

$$
\mathrm{CH}_{3}+\mathrm{H} \rightarrow \mathrm{CH}_{4}
$$



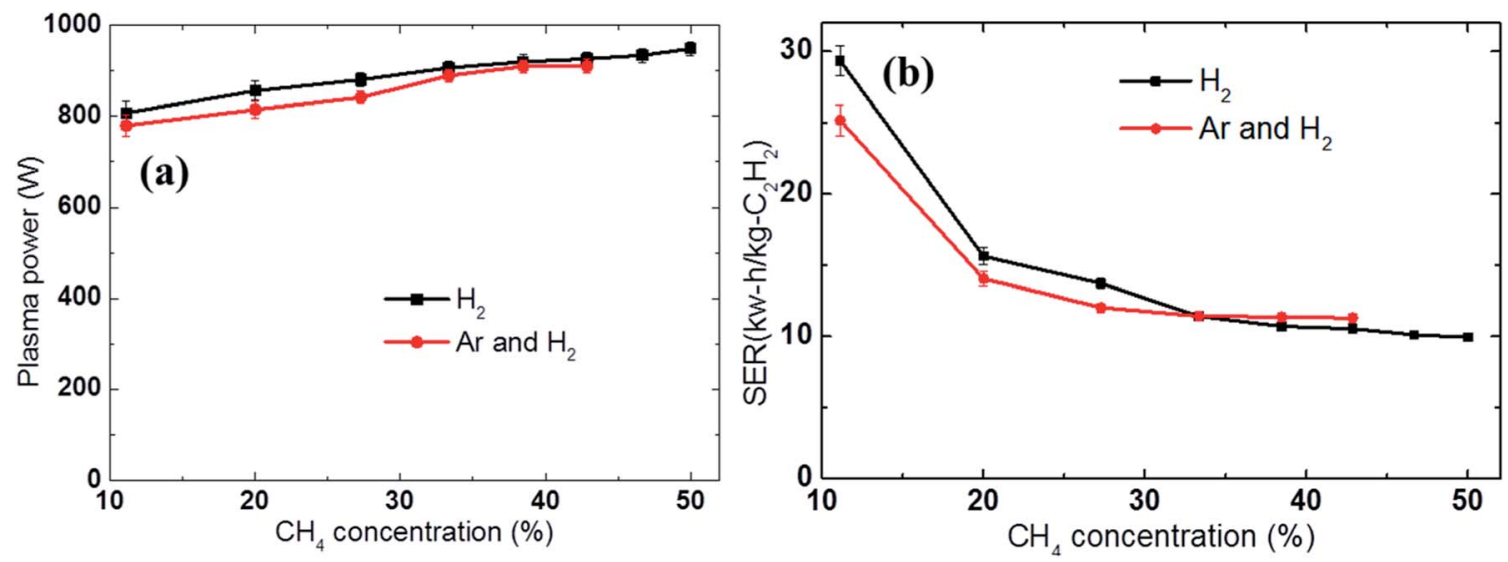

Fig. 4 Effect of the methane feed rate on the (a) plasma power and (b) energy cost (SER) using either $\mathrm{H}_{2}(8 \mathrm{SLPM})$ or an $\mathrm{Ar}$ and $\mathrm{H}_{2}$ mixture (4 SLPM of $\mathrm{Ar}$ and $4 \mathrm{SLPM}$ of $\mathrm{H}_{2}$ ) as the discharge gas.

In comparison, Ar dilution has only a weak effect on the reaction kinetics of the methane conversion process. Increasing the Ar concentration can enhance Ar excitation ( $\left.\mathrm{Ar}^{*}\right)$ and $\mathrm{Ar}$ ionization $\left(\mathrm{Ar}^{+}\right)$, inducing methane conversion via direct collisions, as in eqn (11) and (12). ${ }^{42-53}$ However, the previous studies reported that thermal activation is the main contributor in arc plasma processes, whereas the effect of direct collisions (the nonthermal effect) is smaller. ${ }^{50,51}$ As a result, the effect of Ar dilution on the reaction kinetics of methane conversion is negligible.

$$
\begin{aligned}
& \mathrm{CH}_{4}+\mathrm{Ar}^{*} \rightarrow \mathrm{CH}_{y}+(4-y) \mathrm{H}+\mathrm{Ar} \\
& \mathrm{CH}_{4}+\mathrm{Ar}^{+} \rightarrow \mathrm{CH}_{y}+(4-y) \mathrm{H}+\mathrm{Ar}
\end{aligned}
$$

In this study, the acceleration of the backward reactions by hydrogen during methane conversion was clearly observed at low methane concentrations. For example, at a $20 \%$ methane concentration (2 SLPM of $\mathrm{CH}_{4}$ ), the use of $\mathrm{H}_{2}$ as the discharge gas (8 SLPM of $\mathrm{H}_{2}, \mathrm{H}_{2} / \mathrm{CH}_{4}=4$ ) resulted in a significantly lower methane conversion ( $83 \%$ vs. $91 \%$, a decrease of $8 \%$ ) compared to the mixed gas (4 SLPM of Ar mixed with 4 SLPM of $\mathrm{H}_{2}, \mathrm{H}_{2} / \mathrm{CH}_{4}$ $=2$ ), as shown in Fig. 5 a.
A comparison of the product selectivity and carbon balance showed that the use of $\mathrm{H}_{2}$ as the discharge gas rather than the $\mathrm{Ar}$ and $\mathrm{H}_{2}$ mixture resulted in a slightly higher hydrocarbon selectivity (Fig. $5 b$ ). For example, the $\mathrm{C}_{2} \mathrm{H}_{2}$ selectivity achieved using the hydrogen discharge gas was approximately $2 \%$ higher than that observed when the $\mathrm{Ar}$ and $\mathrm{H}_{2}$ mixture was used $(94.7 \%$ vs. $92.2 \%$, respectively). This shows that in addition to accelerating the reverse reactions, $\mathrm{H}_{2}$ also partially suppresses soot formation. As a result of the dramatically reduced methane conversion at low $\mathrm{CH}_{4}$ concentrations (e.g., 20\%), the SER was higher for the hydrogen discharge gas than for the $\mathrm{Ar}$ and $\mathrm{H}_{2}$ mixture (15.6 kW h kg ${ }^{-1} \mathrm{C}_{2} \mathrm{H}_{2}$ vs. $14 \mathrm{~kW} \mathrm{~h} \mathrm{~kg}^{-1} \mathrm{C}_{2} \mathrm{H}_{2}$, respectively), as shown in Fig. $4 \mathrm{~b}$.

In contrast, at high $\mathrm{CH}_{4}$ concentrations (e.g., $43 \%$ and 6 SLPM of $\left.\mathrm{CH}_{4}\right), \mathrm{H}_{2}$ mainly participates in suppressing solid carbon formation, increasing the acetylene selectivity. Fig. 5b shows that the use of $\mathrm{H}_{2}$ as the discharge gas $\left(\mathrm{H}_{2} / \mathrm{CH}_{4}=4 / 3\right)$ resulted in significantly (9\%) higher acetylene selectivity than when the Ar and $\mathrm{H}_{2}$ mixture was used $\left(\mathrm{H}_{2} / \mathrm{CH}_{4}=2 / 3\right)$, while the conversion was only slightly lower (1\%), respectively. Although the soot formation was not measured quantitatively during this
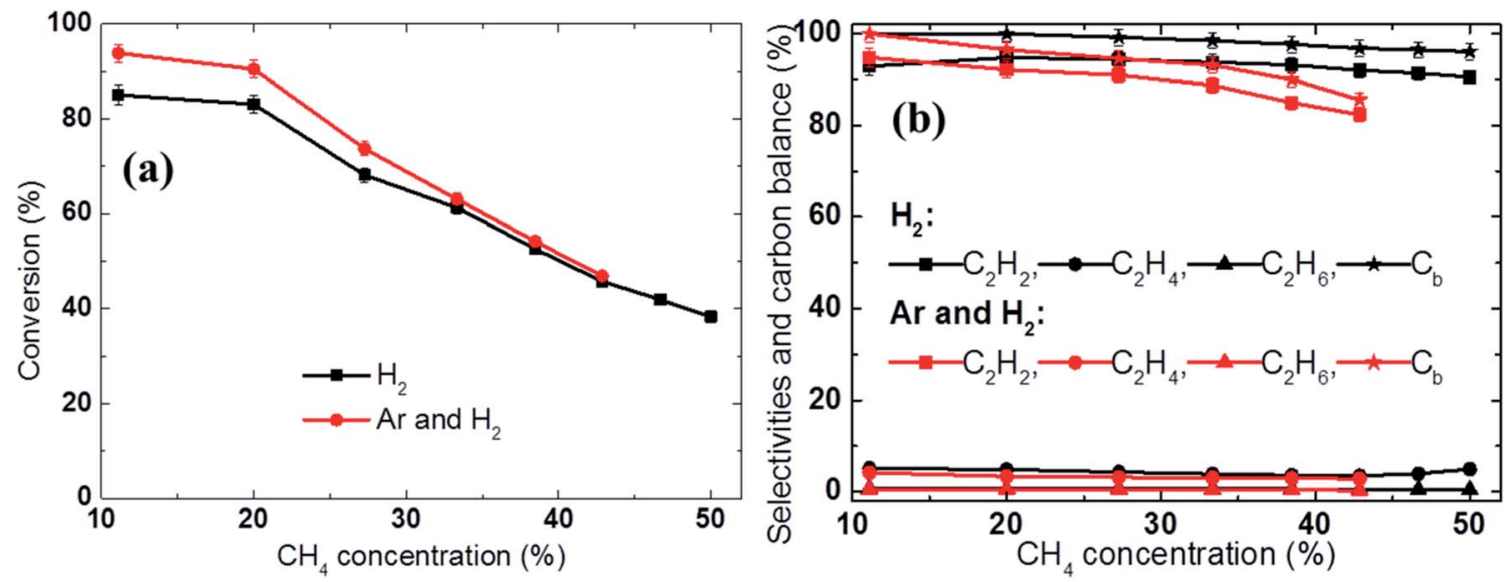

Fig. 5 Effect of the methane feed rate on the (a) conversion and (b) selectivity and carbon balance using either $\mathrm{H}_{2}$ (8 $\mathrm{SLPM}$ ) or an Ar and $\mathrm{H}_{2}$ mixture (4 SLPM of Ar and 4 SLPM of $\mathrm{H}_{2}$ ) as the discharge gas. 
study, the carbon balance of $96 \%$ in the $\mathrm{H}_{2}$ discharge gas compared to $86 \%$ in the $\mathrm{Ar}$ and $\mathrm{H}_{2}$ discharge gas indirectly demonstrated that a higher hydrogen concentration significantly reduced soot formation. As a result, the use of the $\mathrm{H}_{2}$ as the discharge gas reduced the SER by $9 \%$ versus that obtained using the $\mathrm{Ar}$ and $\mathrm{H}_{2}$ mixture at $42.8 \% \mathrm{CH}_{4}$ concentration (10.5 $\mathrm{kW} \mathrm{h} \mathrm{kg}{ }^{-1} \mathrm{C}_{2} \mathrm{H}_{2}$ in the $\mathrm{H}_{2}$ discharge gas versus $11.2 \mathrm{~kW} \mathrm{~h} \mathrm{~kg}^{-1}$ $\mathrm{C}_{2} \mathrm{H}_{2}$ in the Ar and $\mathrm{H}_{2}$ mixture, respectively), see Fig. $4 \mathrm{~b}$.

In summary, for methane concentrations from $38.5 \%$ to $50 \%$, the use of $\mathrm{H}_{2}$ as the additive gas reduces the energy cost and results in relatively high acetylene selectivity and high carbon balance or low soot formation.

\subsection{SEI effect}

Increasing the SEI increases the supply of heat during this type of process, in which plasma is the main heat source for the activation of the reaction. Given this, it is natural to expect higher conversion of the reactants under higher SEI conditions; this expectation was fulfilled during the experiments in which the temperature measured $60 \mathrm{~mm}$ downstream from the nozzle was $780{ }^{\circ} \mathrm{C}$ and $1068{ }^{\circ} \mathrm{C}$ for an SEI of $3.9 \mathrm{~kJ} \mathrm{~L}^{-1}$ and $6 \mathrm{~kJ} \mathrm{~L}^{-1}$, respectively. The different temperatures also resulted in different methane conversions of $43 \%$ and $68 \%$, respectively, as shown in Fig. 6a. Thus, an increase in the acetylene concentration was achieved by increasing the electric power. For example, the $\mathrm{C}_{2} \mathrm{H}_{2}$ concentration increased from $7 \%$ to $10.6 \%$, while the energy cost of acetylene production remained unchanged $10.2 \mathrm{~kW} \mathrm{~h} \mathrm{~kg}{ }^{-1} \mathrm{C}_{2} \mathrm{H}_{2}$ when the electric power was increased from $3.9 \mathrm{~kJ} \mathrm{~L}^{-1}$ to $6 \mathrm{~kJ} \mathrm{~L}^{-1}$, as shown Fig. $6 \mathrm{~b}$. The acetylene selectivity and carbon balance were not dependent on the SEI, nor did they show any meaningful change, because the increase in the temperature inside the reactor due to additional heat or SEI did not produce an environment in which acetylene could undergo subsequent pyrolysis, but did make the further conversion of methane more favorable. Below the upper limit of the SEI at which the acetylene begins to decompose into carbon, increasing the SEI increases the conversion of methane and the concentration of the product acetylene.

\section{Discussion}

The high carbon balance in Case 1 (Fig. $3 \mathrm{~b}$ ) ensures that the possible deterioration of arc generation due to the formation of solid carbon is effectively suppressed. The carbon balance in Case 2 is nearly $100 \%$ except at the highest SEI. This means that the temperature in the jet (downstream of the nozzle) was below the threshold temperature for the thermal pyrolysis of the produced acetylene. However, the carbon balance in Case 1 is relatively lower (but still much greater than 90\%), implying that the methane is subjected to much higher temperatures in the arc region than in the jet region. However, even given the high temperature in the arc region, a carbon balance of greater than $90 \%$ can be achieved by controlling the reaction time. Based on the flow rate and the reactor geometry, the estimated time scale of the methane conversion reaction, that is, the time required for the flow to pass from the tip of the high-voltage electrode to the nozzle, was approximately $3 \mathrm{~ms}$. As shown in Fig. 1, this time scale lies within the range at which a high acetylene yield and reduced solid carbon generation can be achieved at temperatures lower than $1800^{\circ} \mathrm{C}$. The result implies that a welldesigned reactor geometry can provide a sufficiently short time scale for the reaction, suppressing solid carbon generation.

Anchoring the arc on the nozzle inlet resulted in intensive heating near the arc spot. The heat released in the nozzle inlet by rotating the arc spot enabled rapid heating of the methane feed stream as it flowed past. Although it is possible for methane to come into contact with the arc string in zone I, most of the heat transfer and subsequent pyrolysis take place in the narrow region at the inlet of the nozzle, as shown in Fig. 7. The effective time scale of the reaction is estimated to be less than $1 \mathrm{~ms}$, which is very favorable for the suppression of carbon generation and the resultant lowering of the temperature for the conversion of methane to acetylene. The endothermic reaction and heat loss to the outside of the reactor consume heat in most of the reactive region, and the temperature gradient in the nozzle inlet area is large. Thus, the temperature in zone II results in less reactivity and does not induce further pyrolysis of the product. This is the
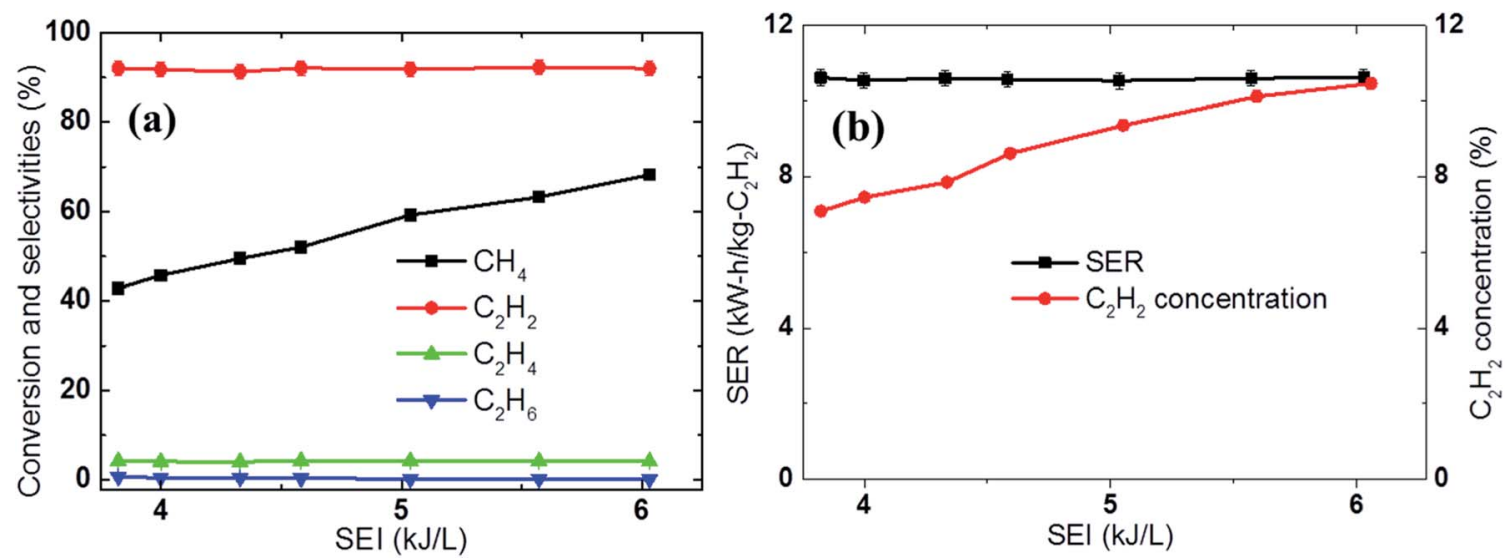

Fig. 6 Effect of the SEI on the (a) conversion, selectivity, and carbon balance and (b) SER and $\mathrm{C}_{2} \mathrm{H}_{2}$ concentration using CH 4 (6 SLPM) and $\mathrm{H}_{2}(8$ SLPM). 


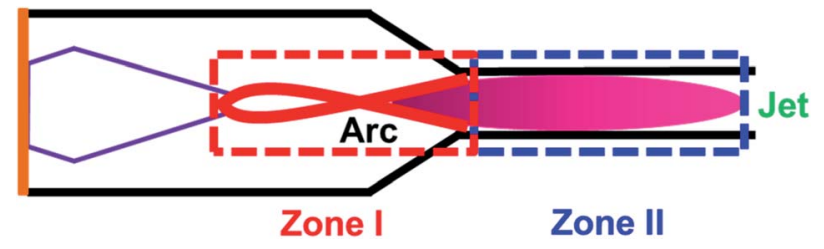

Fig. 7 Methane conversion in the novel rotating arc reactor, classified into two reaction zones.

key feature of the proposed novel reactor design, enabling a high carbon balance and high selectivity for acetylene.

In comparison to other well-known plasma approaches that have been employed to induce the direct conversion of methane to acetylene, our novel rotating arc technology has a lower SER than the Hüels process $\left(10.2 \mathrm{~kW} \mathrm{~h} \mathrm{~kg}^{-1} \mathrm{C}_{2} \mathrm{H}_{2} v s .12 .1 \mathrm{~kW} \mathrm{~h} \mathrm{~kg}^{-1}\right.$ $\mathrm{C}_{2} \mathrm{H}_{2}$, respectively). The lower SER is due to the differences in (1) the methane feeding method and (2) current-voltage characteristics. All the feedstocks are diluted with hydrogen gas before being passed through the arc column in our technology, while a fraction of the feedstock is injected downstream of the arc during the Hüels process. Additionally, our technology adopted AC electric power with a lower current (several amperes) and high voltage (several $\mathrm{kV}$ ), while the thermal arc used in the Hüels process utilizes DC electric power with a current of hundreds of amperes and a low voltage.

Due to the re-ignition characteristics, AC can supply more stable continuous discharges compared than DC that reignition is hard to get one detached. In addition, AC source is easier to support a higher potential condition that results in elongation of the arc string. This elongation of the arc string provides a greater volume for mixing and heat transfer in the region labelled as zone I in the proposed reactor design.

In addition to promoting arc stability, the higher voltage and lower current have an additional benefit. In our previous publication, we have extensively investigated the energy balance of the plasma system. We found that lower current conditions, by virtue of the resulting arc elongation, reduced conductive heat loss to the reactor body, which further enhanced heat transfer to the feed gas and enhanced the reaction..$^{51}$ Therefore, the use of low current and high voltage conditions for the elongation of the arc column can reduce the energy cost of direct methane conversion in arc plasma.

In comparison to the methane-to-acetylene conversion in pulsed plasma, to remain a well stable discharge condition in our technology, the methane concentration should be lower than $50 \%$. Meanwhile, pulsed discharge in pure methane is possible. $^{20,54,55}$ Because of this difference, a slightly lower SER in the pulsed discharge can be achieved. For example, SER of 9.2 $\mathrm{kW} \mathrm{h} \mathrm{kg}{ }^{-1} \mathrm{C}_{2} \mathrm{H}_{2}$ has been reported, but the conversion is as low as $23.5 \% .{ }^{55}$ Pulse discharge showed a good SER but high value of conversion was limited.

\section{Conclusion}

A low energy cost $\left(10.2 \mathrm{~kW} \mathrm{~h} \mathrm{~kg}^{-1} \mathrm{C}_{2} \mathrm{H}_{2}\right)$ for the direct conversion of methane to acetylene was obtained by employing low current AC rotating arc technology and optimizing the experimental conditions. The generation of the plasma using AC power rather than DC power is beneficial in terms of arc stability, while the use of a low-current arc rather than a highcurrent arc is beneficial in terms of reducing conductive heat loss to the reactor body, resulting in more heat transfer to the feed gas. To obtain a low energy cost, the $\mathrm{CH}_{4}$ feed rate should be greater than $43 \%$, and the $\mathrm{CH}_{4}$ should be diluted with $\mathrm{H}_{2}$ discharge gas before being passed through the arc column. The acetylene yield is primarily determined by the electrical energy input; increasing the electric power increases the acetylene yield via increased $\mathrm{CH}_{4}$ conversion, resulting in a higher $\mathrm{C}_{2} \mathrm{H}_{2}$ concentration in the product. This work figured out the optimal conditions for a low specific energy requirement in methane-toacetylene conversion in arc plasma.

This study also provides experimental evidence of the effect of $\mathrm{H}_{2}$ on the reaction pathway of direct methane conversion, demonstrating the effect of $\mathrm{H}_{2}$ dilution on the SER for the first time. $\mathrm{H}_{2}$ mainly depresses carbon formation to increase acetylene selectivity at a high methane concentration, while it strongly accelerates the reverse reactions to inhibit $\mathrm{CH}_{4}$ conversion at a low methane concentration. As a result, the use of $\mathrm{H}_{2}$ discharge gas significantly reduces the SER compared to an $\mathrm{Ar}$ and $\mathrm{H}_{2}$ mixture (a decrease of $9 \%$ at a methane concentration of $42.8 \%)$.

\section{Conflicts of interest}

There are no conflicts to declare.

\section{Acknowledgements}

This work was supported by the Institutional Research Program NK219E.

\section{References}

1 X. Wang, Y. Gao, S. Zhang, H. Sun, J. Li and T. Shao, Nanosecond pulsed plasma assisted dry reforming of $\mathrm{CH}_{4}$ : the effect of plasma operating parameters, Appl. Energy, 2019, 243, 132.

2 S. Bhatia, C. Y. Thien and A. R. Mohamed, Oxidative coupling of methane (OCM) in a catalytic membrane reactor and comparison of its performance with other catalytic reactors, Chem. Eng. J., 2009, 148, 525.

3 Z. Yu, X. Yang, J. H. Lunsford and M. P. Rosynek, Oxidative Coupling of Methane over $\mathrm{Na}_{2} \mathrm{WO}_{4} / \mathrm{CeO}_{2}$ and related Catalysts, J. Catal., 1995, 154, 163.

4 S. B. Derouane-Abd Hamid, J. Ross Anderson, I. Schmidt, C. Bouchy, J. Claus, H. Jacobsen and E. G. Derouane, Effect of the activation procedure on the performance of $\mathrm{Mo} / \mathrm{H}$ MFI catalysts for the non-oxidative conversion of methane to aromatics, Catal. Today, 2000, 63, 461.

5 E. Delikonstantis, M. Scapinello and G. D. Stefanidis, Low energy cost conversion of methane to ethylene in a hybrid plasmacatalytic reactor system, Fuel Process. Technol., 2018, 176, 33 . 
6 X. Guo, G. Fang, G. Li, H. Ma, H. Fan, Y. Liang, C. Ma, X. Wu, D. Deng, M. Wei, D. Tan, S. Rui, S. Zhang, J. Li, L. Sun, Z. Tang, X. Pan and X. Bao, Direct, Nonoxidative Conversion of Methane to Ethylene, Aromatics, and Hydrogen, Science, 2014, 344, 616.

7 D. H. Lee, Y.-H. Song, K.-T. Kim and J.-O. Lee, Comparative Study of Methane Activation Process by Different Plasma Sources, Plasma Chem. Plasma Process., 2013, 33, 647.

8 T. Nozaki, A. Bogaerts, X. Tu and R. van de Sanden, Special issue: Plasma Conversion, Plasma process and polymers, 2017.

9 H.-s. Kang, D. h. Lee, K.-t. Kim, S. Jo, S. Pyun, Y.-h. Song and $\mathrm{S}$. Yu, Methane to acetylene conversion by employing costeffective low-temperature arc, Fuel Process. Technol., 2016, 148, 209.

10 T. Li, C. Rehmet, Y. Cheng, Y. Jin and Y. Cheng, Experimental Comparison of Methane Pyrolysis in Thermal Plasma, Plasma Chem. Plasma Process., 2017, 37, 1033.

11 W. R. Bao, Y. L. Tian, F. Li, Y. K. Lv and K. C. Xie, Methane pyrolysis to acetylene under arc plasma, J. Chem. Ind. Eng., 2008, 2, 472 .

12 N. Itoh, W.-C. Xu and A. M. Sathe, Capability of permeate hydrogen through palladium-based membranes for acetylene hydrogenation, Ind. Eng. Chem. Res., 1993, 32, 2614.

13 Q. Zhang, L. Jia, X. Liu and Q. Zhu, Synergetic effect of Pd and $\mathrm{Ag}$ dispersed on $\mathrm{Al}_{2} \mathrm{O}_{3}$ in the selective hydrogenation of acetylene, Appl. Catal., A, 2000, 197, 221.

$14 \mathrm{~W}$. H. Ross, J. B. Culbertson and J. P. Parsons, The Preparation of Ethylene by Hydrogenation of Acetylene, $J$. Ind. Eng. Chem., 1921, 3, 775.

15 A. Fridman, Plasma chemistry, 2008.

16 M. Laroussi and T. Akan, Arc-Free Atmospheric Pressure Cold Plasma Jets: A Review, Plasma Processes Polym., 2007, 4, 777.

17 R. Snoeckx, Y. X. Zeng, X. Tu and A. Bogaerts, Plasma-based dry reforming: improving the conversion and energy efficiency in a dielectric barrier discharge, RSC Adv., 2015, 5, 29799.

18 S. Zhang, Y. Gao, H. Sun, B. Han, R. Wang and T. Shao, Timeresolved characteristics and chemical kinetics of nonoxidative methane conversion in repetitively pulsed dielectric barrier discharge plasmas, J. Phys. D: Appl. Phys., 2018, 51, 274005.

19 S. Mahammadunnisa, P. Manoj Kumar Reddy and C. Subrahmanyam, Nonthermal plasma assisted coprocessing of $\mathrm{CH}_{4}$ and $\mathrm{N}_{2} \mathrm{O}$ for methanol production, $R S C$ Adv., 2014, 4, 4034.

20 Y. Gao, S. Zhang, H. Sun, R. Wang, X. Tu and T. Shao, Highly efficient conversion of methane using microsecond and nanosecond pulsed spark discharges, Appl. Energy, 2018, 226, 534.

21 H. Zhang, F. Zhu, X. Li, K. Cen, C. Dub and X. Tu, Enhanced hydrogen production by methanol decomposition using a novel rotating gliding arc discharge plasma, RSC Adv., 2016, 6, 12770.
22 B. Ruj and S. Ghosh, Technological aspects for thermal plasma treatment of municipal solid waste-A review, Fuel Process. Technol., 2014, 126, 298.

23 J. R Fincke, R. P Anderson, T. Hyde, B. A. Detering, R. Wright, R. L Bewley, D. C Haggard and W. D Swank, Plasma Thermal Conversion of Methane to Acetylene, Plasma Chem. Plasma Process., 2002, 22, 105.

24 P. Passler, W. Hefner, K. Buckl, H. Meinass, A. Meiswinkel, H. Wernicke, G. Ebersberg, R. Müller, J. Bassler, H. Behringer and D. Mayer, Acetylene, in Ullmann's Encyclopedia of Industrial Chemistry, 2008.

25 Q. Zhang, J. Wang and T. Wang, Enhancing the Acetylene Yield from Methane by Decoupling Oxidation and Pyrolysis Reactions: A Comparison with the Partial Oxidation Process, Ind. Eng. Chem. Res., 2016, 55, 8383.

26 K. V. Dobrego, N. N. Gnesdilov, S. H. Lee and H. K. Choi, Overall chemical kinetics model for partial oxidation of methane in inert porous media, Chem. Eng. J., 2008, 144, 79.

27 Y. Liu, T. Wang, Q. Li and D. Wang, A Study of Acetylene Production by Methane Flaming in a Partial Oxidation Reactor, Chin. J. Chem. Eng., 2011, 19, 424.

$28 \mathrm{E}$. Bartjiolome, the BASF-process for production of acetylene by partial oxidation of gaseous hydrocarbons, Chem. Eng. Sci., 1954, 3, 94.

29 Q. Zhang, J. Wang and T. Wang, Effect of Ethane and Propane Addition on Acetylene Production in the Partial Oxidation Process of Methane, Ind. Eng. Chem. Res., 2017, 56, 5174.

30 M. J. P. Bogart and R. H. Long, Pyrolysis of liquid hydrocarbons via the Wulff process, Chem. Eng. Prog., 1962, 58, 91.

31 J. Weill, C. J. Cameron and C. Raimbault, Direct conversion of methane: IFP (French Petroleum Institute) processes, Riv. Combust., 1991, 45, 147.

32 P. Broutin, C. Busson, J. Weill and F. Billaud, in Novel Production Methods for Ethylene, Light Hydrocarbons and Aromatics, 1991, p. 239.

33 A. Holmen, O. Olsvik and O. A. Rokstad, Pyrolysis of natural gas: chemistry and process concepts, Fuel Process. Technol., 1995, 42, 249.

34 J. R. Roth, Industrial Plasma Engineering, Volume 1: Principles, 1995.

35 H. Gladish, How Huels makes acetylene by DC arc, Hydrocarbon Process. Pet. Refin., 1962, 41, 159.

36 Anon, New burner opens door to arc acetylene, Chem. Week, 1964, 94(3), 64.

37 J. M. Holmes, Evaluation of DuPont arc process for acetylene and vinyl chloride monomer production, 1969.

38 A. Holmen, O. A. Rokstad and A. Solbakken, HighTemperature Pyrolysis of Hydrocarbons. 1. Methane to Acetylene, Ind. Eng. Chem. Process Des. Dev., 1976, 15, 439.

39 O. Olsvik and A. Odd, Rokstad and Anders Holmen, Pyrolysis of methane in the Presence of Hydrogen, Chem. Eng. Technol., 1995, 18, 349.

40 J. R. Fincke, R. P. Anderson, T. A. Hyde and B. A. Detering, Plasma Pyrolysis of Methane to Hydrogen and Carbon Black, Ind. Eng. Chem. Res., 2002, 41, 1425. 
41 R. F. Baddour and J. L. Blanchet, Reaction of carbon vapor with hydrogen and with methane in a high intensity arc, I\&EC Process Des. Dev., 1964, 3, 258.

42 A. V. Krestinin, Detailed Modeling of Soot Formation in Hydrocarbon Pyrolysis, Combust. Flame, 2000, 121, 513.

43 M. Dors, H. Nowakowska, M. Jasiński and J. Mizeraczyk, Chemical Kinetics of Methane Pyrolysis in Microwave Plasma at Atmospheric Pressure, Plasma Chem. Plasma Process., 2014, 34, 313.

44 D. H. Lee, K. T. Kim, M. S. Cha and Y. H. Song, Optimization scheme of a rotating gliding arc reactor for partial oxidation of methane, Proc. Combust. Inst., 2007, 31, 3343.

45 D. H. Lee, K. T. Kim, Y. H. Song, W. S. Kang and S. K. Jo, Mapping plasma chemistry in hydrocarbon fuel processing processes, Plasma Chem. Plasma Process., 2013, 33, 249.

46 D. H. Lee, K.-T. Kim, M. S. Cha and Y.-H. Song, Plasmacontrolled chemistry in plasma reforming of methane, Int. J. Hydrogen Energy, 2010, 35, 10967.

47 H. Zhang, X. Li, F. Zhu, K. Cen, C. Du and X. Tu, Plasma assisted dry reforming of methanol for clean syngas production and high-efficiency $\mathrm{CO}_{2}$ conversion, Chem. Eng. J., 2017, 310, 114.

48 D. K. Dinh, H. S. Kang, S. Jo, D. H. Lee and Y.-H. Song, Partial oxidation of diesel fuel by plasma: Kinetic aspects of the reaction, Int. J. Hydrogen Energy, 2017, 42, 22756.
49 D. H. Lee, K.-T. Kim, H. S. Kang, S. Jo and Y.-H. Song, Optimization of $\mathrm{NH}_{3}$ Decomposition by Control of Discharge Mode in a Rotating Arc, Plasma Chem. Plasma Process., 2014, 34, 111.

50 D. K. Dinh, S. Choi, D. H. Lee, S. Jo, K.-T. Kim and Y.-H. Song, Energy efficient dry reforming process using low temperature arcs, Plasma process and polymers, 2018.

51 D. K. Dinh, D. H. Lee, Y.-H. Song, S. Jo and K.-T. Kim, Arc length control for efficiency enhancement of energy usage in plasma dry reforming process, J. $\mathrm{CO}_{2}$ Util., 2018, 28, 274.

52 S. Jo, D. H. Lee, W. S. Kang and Y.-H. Song, Methane activation using noble gases in a dielectric barrier discharge reactor, Phys. Plasmas, 2013, 20, 083509.

53 V. Goujard, J.-M. Tatibouët and C. Batiot-Dupeyrat, Carbon Dioxide Reforming of Methane Using a Dielectric Barrier Discharge Reactor: Effect of Helium Dilution and Kinetic Model, Plasma Chem. Plasma Process., 2011, 31, 315.

54 R. Lotfalipour, A. M. Ghorbanzadeh and A. Mahdian, Methane conversion by repetitive nanosecond pulsed plasma, J. Phys. D: Appl. Phys., 2014, 47, 365201.

55 S. L. Yao, E. Suzuki, N. Meng and A. Nakayama, A HighEfficiency Reactor for the Pulsed Plasma Conversion of Methane, Plasma Chem. Plasma Process., 2002, 22, 225. 